\title{
Presídios de Mulheres são Espaços Femininos? 0 Poder da Heteronormatividade no Sistema Prisional Carioca
}

\author{
Are the Female Prisons Spaces of Women? The Power of Heteronormativity in \\ the Prison System Rio de Janeiro
}

\author{
Mariana Coelho Torres \\ Pontifícia Universidade Católica do Rio de Janeiro \\ maricatorres22@hotmail.com \\ Augusto Cesar Pinheiro da Silva \\ Pontifícia Universidade Católica do Rio de Janeiro \\ acpinheiro08@gmail.com
}

\section{Resumo}

A sociedade ocidental é orientada para a valorização das práticas heterossexuais, moldando espaços e definindo territorialidades, caracterizando-se, fortemente, pela sua heteronormatividade. Os presídios femininos da cidade do Rio de Janeiro são exemplos de espaços produzidos onde as relações interpessoais acontecem baseadas na lógica heteronormativa; todavia, uma parte das mulheres apresenta identidade de gênero masculina e a outra de gênero feminina. Tal condição determina que nas relações lésbicas, os papéis heteronormativos dos gêneros 'masculino' e 'feminino' devem ser seguidos, senão há consequências diversas. Assim sendo, os presídios femininos cariocas constituem um espaço segregador e discriminatório nas relações de gênero, reproduzindo a exclusão a qual os grupos homoafetivos estão fadados no espaço 'livre' da existência social.

Palavras-chave: Espaço, Cárcere Feminino; Heteronormatividade; Gênero; Sexualidades.

\begin{abstract}
Western society is oriented towards the exploitation of heterosexual practices, shaping and defining space territorialities strongly characterized by their heteronormativity. The female prisons in the city of Rio de Janeiro are examples of produced spaces where interpersonal relationships happen based on a heteronormative logic; however, some women experience male gender identity, while others experience female gender. This condition states that, in lesbian relationships, the heteronormative gender roles of 'male' and 'female' must be followed, or else there would be several consequences. Thus, the female prisons in Rio constitute a segregative and discriminatory space in gender relations, reproducing the exclusion to which homosexual groups are bound even in the 'free' space of social existence.
\end{abstract}

Keywords: Space; Female Prisons; Heteronormativity; Gender; Sexualities. 


\section{Introdução}

Nosso trabalho tem como objetivo identificar a construção e organização espacial do modelo heteronormativo em presídios femininos. Para isto, acatamos a crítica à concepção de gênero exclusivamente ligada ao sexo e buscamos, através do conhecimento geográfico, compreender como as questões de gênero e sexualidades estão ligadas à qualidade do sistema prisional brasileiro. A partir dessas questões, mostramos que é possível melhorar as condições carcerárias no país, especialmente nas instituições que atendem a população do sexo feminino. Neste contexto, a sociedade heteronormativa reflete-se nos mais variados espaços a partir das normatividades heterossexuais, sendo elas as únicas possíveis de serem acatadas e aceitas no imaginário social e comportamental de grande parte das sociedades ocidentais atuais.

As dinâmicas espaciais ligadas às questões penais de gênero e sexualidades ganham, na atualidade, intensidade na investigação acadêmica frente à necessidade de serem expostas à sociedade as entranhas de um sistema penal inoperante, que expõe a fragilidade das conquistas sociais no Brasil, do seu sistema punitivo e de controle da segurança pública, mas que encontra respaldo em expressiva parcela da sociedade brasileira para quem "bandido bom é bandido morto"1. A promoção da conscientização social acerca da população carcerária brasileira é de especial importância para a democratização de direitos em todos os níveis, no país, e políticas públicas específicas de atenção a mulheres encarceradas não podem ser banalizadas.

No contexto de uma sociedade heteronormativa, patriarcal e hierárquica (SILVA, 2009), a condição de ser 'mulher presidiária' define seres humanos silenciados em uma sociedade já muito desigual e segregadora e, assim sendo, é hora de dar voz a elas através dos canais competentes, tornando-as visíveis e dignificadas para as intervenções dos poderes públicos. Apesar da aparente distância explicada pelo preconceito e pelo medo, o sistema carcerário é próximo da nossa realidade (FIORAVANTE, 2009), sendo os detentos(as) e ex-detentos(as) parte da nossa sociedade. Este trabalho pretende dar importância às presas do sistema carcerário do Rio de Janeiro (RJ), mas também provocar uma reflexão da Academia sobre as relações entre o poder e o gênero existente em um grupo social (mulheres encarceradas) pouco visível e sem força política para promover melhorias nas suas condições de vida.

A categoria 'espaço', aqui neste trabalho, é compreendida como o lócus das interações e relações humanas (SANTOS, 1996), e a do 'território' como aquele das dimensões material e simbólica promovidas pela política, identidade e afetividade (HAESBAERT, 2002). Tais categorias 'da Geografia' serão associadas às de 'gênero' e 'sexualidade' propostas por Butler (1990) e Silva (2009), além da categoria 'poder' encontrada em Foucault (1987). Partindo-se da premissa de que o gênero é uma construção social e que este não é determinado pelo sexo (BUTLER, 1990), não deve existir linearidade entre gênero, sexo e desejo num modelo pré-estabelecido seguido na vivência temporal e espacial da sexualidade. Assim sendo, ao estudarmos os presídios femininos, observamos que a não linearidade anteriormente reconhecida é vista na construção de um ambiente carcerário reprodutor da heteronormatividade da sociedade ocidental, e que tal construção hierarquiza e desigualiza as relações sociais internas, pois as representações de gênero são estratégia de controle territorial, portanto de poder, na construção da espacialidade das mulheres encarceradas. 
Os procedimentos metodológicos para a elaboração da pesquisa ${ }^{2}$ sobre a qual este artigo foi escrito podem ser classificados como qualitativos, sendo executados por observação indireta, complementando-se com o fichamento da bibliografia principal e a aplicação de entrevistas semi-estruturadas a mulheres ex-presidiárias. Também foram analisadas fotografias pessoais das detentas e cartas escritas por/e para presas.

Como podemos relacionar as questões de gênero e sexualidades com o cárcere e a geografia? Todos esses aspectos possuem um componente em comum: o espaço. Inicialmente a ideia da pesquisa era trabalhar com presas internas do sistema penitenciário da cidade do Rio de Janeiro (RJ), todavia, para a execução de qualquer pesquisa formal em algum estabelecimento prisional dessa unidade federada é necessária à autorização da Secretaria Estadual de Administração Penitenciária, através de um processo administrativo. No nosso caso, o processo foi indeferido sem nenhuma justificativa e a pesquisa não autorizada. Nós entendemos o indeferimento como a não valorização das relações de gênero na produção da Geografia $^{3}$, bem como da importância de sua consideração na gestão pública atual. Decidimos, então, trabalhar com experiências empíricas de um momento anterior ${ }^{4}$, utilizando fotos e cartas de internas e, principalmente, com entrevistas de egressas do sistema penal carioca.

Além da não autorização acima exposta, enfrentamos outra grande dificuldade para a realização da pesquisa: a ainda escassa bibliografia sobre a área de Geografia e Gênero em língua portuguesa e na Geografia brasileira $^{5}$. Além dessas dificuldades, houve ainda o receio das ex-detentas em conceder entrevistas, resistência essa que foi sendo rompida a partir da confiança adquirida por algumas delas durante as conversas informais, o que culminou em importantes relatos sobre a trama da investigação em curso, apesar do medo de retaliações ${ }^{6}$.

Mesmo o nosso trabalho se debruçando sobre a categoria 'gênero' é importante ressaltar que nenhum estudo espacial deve ser entendido somente por esta ótica, pois as sociedades são constituídas por muitas outras relações além das de gênero como as de sexualidades, classes, etnia e outras que fazem parte da vida de pessoas que se identificam em grupos impressos no espaço. Nesse contexto, faz-se de suma importância que os geógrafos tenham uma visão complexa da realidade, associando diversas dimensões e categorias de análise.

\section{A construção da sociedade heteronormativa: algumas considerações sobre o conceito de gênero na geografia}

A criação de uma sociedade, sua ideologia e seus costumes é decorrente de um processo construído em um diálogo com o 'outro' (HALL, 1992). Na atualidade, nas sociedades normatizadas por territórios em que vivemos, ainda predominam as perspectivas ideológicas ocidentais ${ }^{7}$. Tal perspectiva gera, constantemente, a reconstrução das formas de pensar, agir, produzir, etc., dominando os espaços e desconsiderando o 'outro': as particularidades de cada lugar, cada indivíduo, cada sociedade. A sociedade ocidental é orientada para a valorização das práticas sociais heterossexuais, constituindo o que chamamos de sociedade heteronormativa. Essa característica é resultado de um processo gerado pela imposição de valores homogeneizantes, construídos e fortalecidos no bojo da ocidentalização do mundo (SILVA, 2009). Tal imposição molda espaços, define territorialidades e hierarquiza sociedades, e, como consequência, a realidade é vivida e concebida sob a ótica da heteronormatividade e as pessoas que se comportam de maneira diferente estão à 
margem da normalidade dominante.

Nesse contexto, o conceito de gênero é compreendido de maneira discriminatória, na medida em que a 'normalidade' das identidades no Ocidente é dominantemente atrelada à heterossexualidade, que concebe os ideais de masculinidade e feminilidade, a partir dos sexos biológicos de homens e mulheres (SILVA, 2009). Todavia, como salienta Butler (1990), o gênero não é uma categoria fixa, pois que se (re)constrói, a cada dia, por meio do comportamento do 'sujeito generificado' e este, por sua vez, só é reconhecido na sua esfera social, no espelhamento com o outro, que o diferencia. Assim sendo, o espaço geográfico é permeado por relações de gênero e essas se ressignificam, diariamente, nas relações espaciais cotidianas (FIORAVANTE, 2011). Silva (2009, p.84) reforça essa ideia do sujeito generificado ao afirmar que:

o gênero, (...), não é uma realidade em si mesma, mas um ideal exercitado cotidianamente por diferentes tipos de corpos que, ao agirem pautados pela representação, superam a mera reprodução de papéis e recriam continuamente a própria representação de gênero. Assim, o gênero é um eterno movimento que se faz na ação humana criativa, e como toda ação implica uma espacialidade, o caráter performático do gênero é simultaneamente espacial e temporal.

E ainda que:

(...) o gênero é compreendido para além da mera representação de papéis a serem desempenhados por corpos de homens e mulheres, sob a hegemonia da heteronormatividade; é uma complexidade permanentemente aberta. Assim, gênero é uma representação vivenciada pelas performances dos sujeitos sociais que a experienciam mediante a experiência espacial cotidiana e concreta (p.139-140).

Assim sendo, entendemos que o espaço é vivenciado de diferentes maneiras pelos diferentes grupos sociais e que não deve haver modelos de comportamento préestabelecidos. Nesse sentido, orientar a produção espacial sob a ótica da heteronormatividade constrói e fortalece práticas discriminatórias.

Os transgressores da ordem geral estabelecida são fadados a severas punições, construídas pelas táticas eficazes e sutis da interdição. Do ponto de vista objetivo e legal, a sociedade brasileira não pode mais perpetrar a punição física pela "ordem" do Estado. Mas as penalidades são praticadas, e elas respondem por inúmeras mortes de pessoas consideradas 'anormais' (SILVA, 2009, p.140-141).

Compreendendo que a concepção performática de gênero não é determinada pelo sexo, mas sim como uma construção social que deve ser sempre contextualizada e relativizada (BUTLER, 1990), é possível avançarmos na discussão de que existe uma hierarquia de gêneros devido a uma hierarquia de sexos, estabelecida na sociedade ocidental decorrente do patriarcado $^{8}$. Este, de acordo com as geógrafas feministas, é compreendido:

como um sistema de relações hierarquizadas no qual os seres humanos detêm poderes desiguais, com a supremacia da autoridade masculina sobre a feminina em diversos aspectos da vida social, 


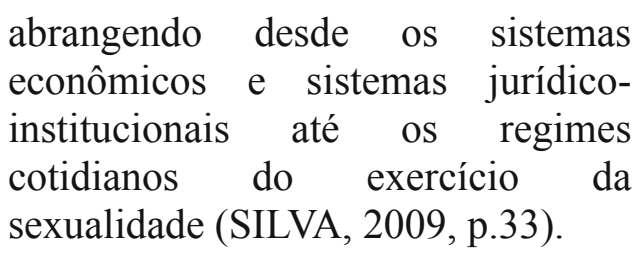

A sociedade é formada por diferentes indivíduos, com diferentes histórias e hábitos, sendo, portanto, plural e, como tal, toda a diversidade que a forma deve ser respeitada ${ }^{9}$. Todavia, a heteronormatividade é claramente expressa no espaço, assim como são claras as práticas discriminatórias decorrentes dessa orientação espacial limitada, pois viola o direito dos indivíduos de se relacionarem, afetivamente, com pessoas do mesmo sexo ou gênero, sendo também segregacionista, na medida em que os grupos sociais que fogem aos modelos de comportamento préestabelecidos são considerados inferiores e mantidos à margem dos direitos sociais. Os presídios femininos da cidade do Rio de Janeiro (RJ) são um exemplo de como a injustiça e a segregação aqui referidas ocorrem na prática. Veremos a seguir, a vivência das sexualidades das internas imposta pela perspectiva heterossexual, mesmo quando as relações afetivas têm perfil homossexual.

\section{Espaços de Opressão Produzidos por Visões Heteronormativas: discriminação de gênero no espaço prisional carioca}

A hegemonia da lógica heteronormativa elimina a diversidade sexual e afetiva na sociedade contemporânea e é responsável pela construção de espaços de opressão e sofrimento, sejam eles públicos ou privados. Entretanto, é nesses mesmos espaços que a mesma lógica pode ser transformada, pois, segundo Silva (2009), eles são os lugares da sua subversão. É no espaço que essa ordem pode ser questionada e a plurinormatividade valorizada.
$\mathrm{Na}$ perspectiva desconstrucionista, o espaço é concebido de forma paradoxal: de um lado, compõe as representações sociais hegemônicas dos gêneros e das sexualidades; de outro, é elemento de subversão dessas mesmas representações, pois é por meio das ações espaciais concretas desempenhadas pelos seres humanos que se dão as contínuas transformações da realidade socioespacial (SILVA, 2009, p.48).

Os espaços produzidos a partir da matriz heterossexual são responsáveis por casos de discriminação que geram sofrimento e morte de inúmeros seres humanos. De acordo com o Grupo Arco-Íris ${ }^{10}$, dois mil e quinhentos homossexuais foram assassinados, no Brasil, entre 2001 e 2011 (dados de 2012) por intolerância de parte daqueles que não aceitam a diversidade pluriafetiva do mundo contemporâneo. Além disso, muitas pessoas convivem com a discriminação, o medo, a baixa autoestima, são violentadas física e simbolicamente por não terem seus direitos reconhecidos em uma legislação pouco abrangente socialmente, o que a torna limitada e segregadora.

Nos espaços plurinormativos redes de solidariedade podem ser estabelecidas a fim de que seja permitida e respeitada a convivência das diversidades de maneira digna, ao abarcar as possibilidades de serem vivenciadas afetividades múltiplas, diferentes sim, mas não desiguais. Assim sendo, entendemos a 'subversão à ordem heteronormativa' como a 'transformação da ordem' e não a sua substituição por outras linearmente homogêneas e limitantes (presentes no discurso reacionário atual da classe média brasileira ao afirmar que as conquistas dos direitos sociais pelos homoafetivos são a imposição de uma 
'ditadura gay' no país). Nós não defendemos aqui a transformação de uma sociedade heteronormativa em outra homonormativa, mas sim a construção de uma sociedade plurinormativa, onde as diferentes práticas sociais sejam respeitadas e valorizadas.

As questões ligadas à normatividade heterossexual são frequentes, apesar de opacas 'para o mundo livre', nos presídios femininos na cidade do Rio de Janeiro (RJ) e as discussões sobre as transgressões ao modelo homogêneo estão absolutamente fechadas na esfera da gestão do sistema prisional, onde se impõe, sem discussões ou estudos para a qualidade de vida no sistema prisional, o silenciamento de pessoas do mesmo sexo biológico que vivem os seus desejos, a partir da rigidez dos padrões de gênero e sexualidade impressos no espaço prisional. Assim sendo, decidimos considerar as vozes das mulheres que um dia passaram pelo sistema prisional (e tiveram suas vidas marcadas por ele) como um testemunho vivo das relações patriarcais e heterônomas vivenciadas nesses 'espaços femininos'.

Os presídios femininos na cidade do Rio de Janeiro (RJ) são um claro exemplo de como as relações de gênero e sexualidade definem as formas de construção e vivência espacial, na medida em que uma parte das mulheres apresenta identidade de gênero masculina e a outra identidade de gênero feminina, obrigatoriamente, criando-se a dicotomização dos desejos intergêneros. Assim sendo, os presídios ${ }^{11}$ são uma oportunidade especial para o estudo das relações humanas, na medida em que, como nos traz Foucault (1987), estes foram constituídos:

fora do aparelho judiciário, quando se elaboraram, por todo o corpo social, os processos para repartir os indivíduos, fixá-los e distribuí-los espacialmente, classificá-los, tirar deles o máximo de tempo, e o máximo de forças, treinar seus corpos, codificar seu comportamento contínuo, mantê-los numa visibilidade sem lacuna, formar em torno deles um aparelho completo de observação, registro e notações, constituir sobre eles um saber que se acumula e se centraliza. A forma geral de uma aparelhagem para tornar os indivíduos dóceis e úteis, através de um trabalho preciso sobre seu corpo, criou a instituição prisão, antes que a lei a definisse como pena por excelência (p.195).

Esse filósofo estruturalista (ou seria pósmoderno?) explica historicamente a formação dos presídios e os diferentes sentidos da punição ao longo do tempo, nos possibilitando compreender suas funções, para além da 'obviedade da prisão-castigo' (FOUCAULT, 1987, p.195). A prisão, segundo o autor, tem como função, além de privar a liberdade, transformar os indivíduos, treinar seus corpos, readequar sua conduta de acordo com as configurações socioespaciais vigentes. No caso das presas que se relacionam como casais homoafetivos, elas reproduzem, por tradição do sistema prisional feminino, a ordem hierárquica de um casal heterossexual tradicional (Imagem 1).

Imagem 1: Casal homoafetivo feminino reproduzindo a heteronormatividade de um casal 'homem-mulher'.

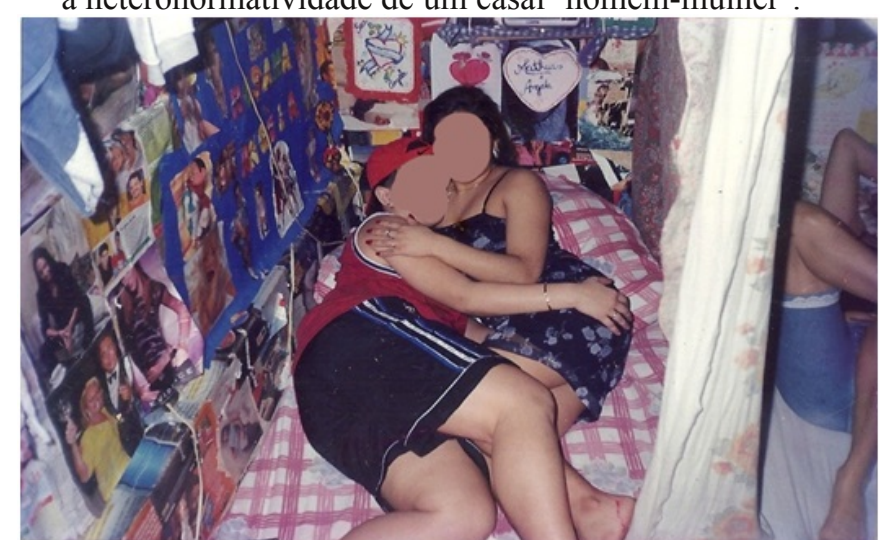

Fonte: Fotografia de arquivo pessoal. Mariana Coelho Torres, 2002. 
Essa realidade faz parte de um código de conduta $^{12}$ que não está escrito em lugar algum, mas todas se comportam assim há gerações, caracterizando a dimensão simbólica ${ }^{13}$ do território lésbico prisional. Existe uma memória comum do grupo de presidiárias que constrói um elemento identitário singular responsável pela construção de hábitos, costumes e normas de comportamento, que caracterizam um modelo único de valores e práticas que afetam a organização territorial nas prisões. As experiências vividas pelas internas nesse código de conduta construído pela memória coletiva (GIDDENS, 1997) reestruturam as experiências espaciais cotidianas (FIORAVANTE, 2011) e orientam o ordenamento daquele território.

Em Bodies that matter, Butler (1993) argumenta que os corpos regidos pelas normas de gênero não estão limitados a executar os padrões hegemônicos de feminilidade ou de masculinidade, tampouco são superfícies pré-existentes e fixas; ao contrário; eles são maleáveis e materializam as identidades de gênero por meio de processos de subjetivação das normas incorporadas, que se expressam nas vivências cotidianas (SILVA, 2009, p.41)

As detentas que quebram essa tradição heteronormativa, comportando-se de 'maneira diferente' daquela historicamente definida por relações do patriarcado ocidental, sofrem consequências, de forma violenta, à feminilidade que as marca como mulheres. Cabelos são cortados violentamente, roupas femininas destruídas, maquiagem e demais acessórios que acompanham o seu cotidiano prisional são inutilizados, além das 'rebeldes' serem atingidas pela violência física dos espancamentos 'masculinos', que doutrinam o seu corpo e psique a tornarem-se 'macho'. Assim sendo, o status quo prisional nega o amor 'entre as iguais', mesmo a homossexualidade sendo aceita nos presídios. Tal aceitação, no entanto, está submetida ao modelo heteronormartivo nas representações sociais daquele espaço, como foi analisado por Ornat (2009, p.185), ao se referir à espacialidade das travestis. Segundo o geógrafo:

(...) no relacionamento, o comportamento de ambos [do mesmo sexo biológico] deve corresponder ao padrão encontrado entre um homem e uma mulher, um comportamento homossexual que busca corresponder a padrões heterossexuais, alinhando-se, paradoxalmente, à heteronormatividade [grifo nosso].

As internas tem uma organização territorial onde o 'macho' é o poderoso, e se organizam em famílias cuja confiança é depositada de uma detenta para outra e suas funções determinadas por uma hierarquia bem definida. Essas são famílias heteronormativas que possuem relações patriarcais, em que cada presa tem sua 'mãe de cadeia', seu 'pai de cadeia', sua 'irmã ou irmão de cadeia', sua 'filha ou filho de cadeia' ${ }^{14}$. O relato de uma ex-detenta clareia essa relação: “(...) no tempo que eu estive lá naquele inferno eu dei sorte porque 'meu pai' era muito poderoso, então não faltava nada pra mim e eu tinha banho de sol todo o dia." (Ana ${ }^{15}$, egressa do sistema penitenciário da cidade do Rio de Janeiro (RJ), 2012). Ou seja, ao possuir um 'pai poderoso', a exdetenta tinha privilégios que só eram possíveis pela força do 'homem' que a protegia. 


\section{Territorialidades dos Casais}

Homoafetivos Heteronormatizados na Estrutura Prisional Feminina: a

\section{identidade masculina do poder prisional}

Nos presídios femininos cariocas a vivência das relações homoafetivas é aceita de forma coletiva, sem que haja proibição ou segregação por parte das demais presas. Os casais formados passam a dividir uma comarca $^{16}$ e a partir de então é como se estivessem casadas (retorno à Imagem 1). Todavia, as presas que não se encaixam nessa ordem heterossexual do espaço prisional (aquelas que assumem identidade feminina de gênero e sentem desejo por presas que também têm identidade feminina ou presas masculinas que desejam presas masculinas) não são aceitas. Portanto, a coletividade e sociabilidade entre os gêneros feminino e masculino devem seguir a ordem heteronormativa, pois reuniões, festividades, atividades culturais, etc., só serão partilhadas por aquelas detentas que respeitam os códigos das relações parentais do contexto binário homem-mulher da sociedade livre, reproduzindo-se, espacialmente, territórios de poder diferenciados (jogos de futebol dos 'homens', atividades de cozinha das 'mulheres', aconselhamento para 'filhos e 'filhas' por 'pais mais velhos' e, portanto, 'mais experientes', etc.), ou seja, a regra dos jogos sociais no sistema prisional feminino reproduz as velhas idiossincrasias das sociedades tradicionais ocidentais, onde a felicidade está no binarismo de gênero e na reprodução das estruturas de poder definidas pela força dos 'homens' no grupo social, ainda que o sexo deles seja o mesmo do das suas 'mulheres' (Imagem 2). Às presas que desejam mulheres do mesmo gênero resta à adequação ou a exclusão ${ }^{17}$.
Imagem 2: Casais homoafetivos formados por presidiárias heteronormatizadas em uma festa de aniversário ('mulheres' de pé, 'homens' agachados).

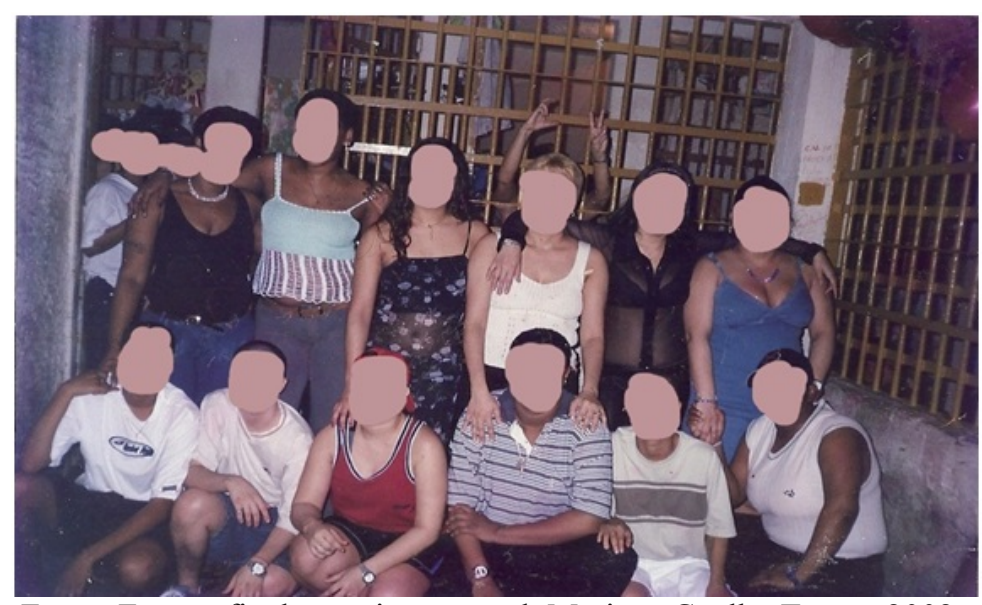

Fonte: Fotografia de arquivo pessoal. Mariana Coelho Torres, 2002.

Nas regras binárias de gênero no sistema prisional feminino, as presas devem conversar com as 'autoridades do coletivo' (que se adequam ao gênero masculino) e apresentar seus desejos, para que seja decidido, pelos guardiões das tradições (GIDDENS, 1997), quem vai exercer os papéis de 'macho' e de 'fêmea'. A partir daí, as presas assumem seus papéis acordados socialmente, e os 'machos' devem transformar seus corpos o máximo possível para que se pareçam como homens.

No trecho de carta enviada por uma presa à sua irmã, podemos ver que a mudança envolve também o apoio dos visitantes e familiares:

(...) estou precisando de muita coisa, mas no momento o que eu mais preciso é de cuecas, camisetas e bermudões, você já deve tá imaginando, mas depois te explico melhor o porquê (...) (Trecho de uma carta enviada por Fernanda, egressa do sistema penitenciário do Rio de Janeiro (RJ), à sua irmã, quando ainda estava presa, em 2012). 
Imagem 3: Presas "masculinas” .

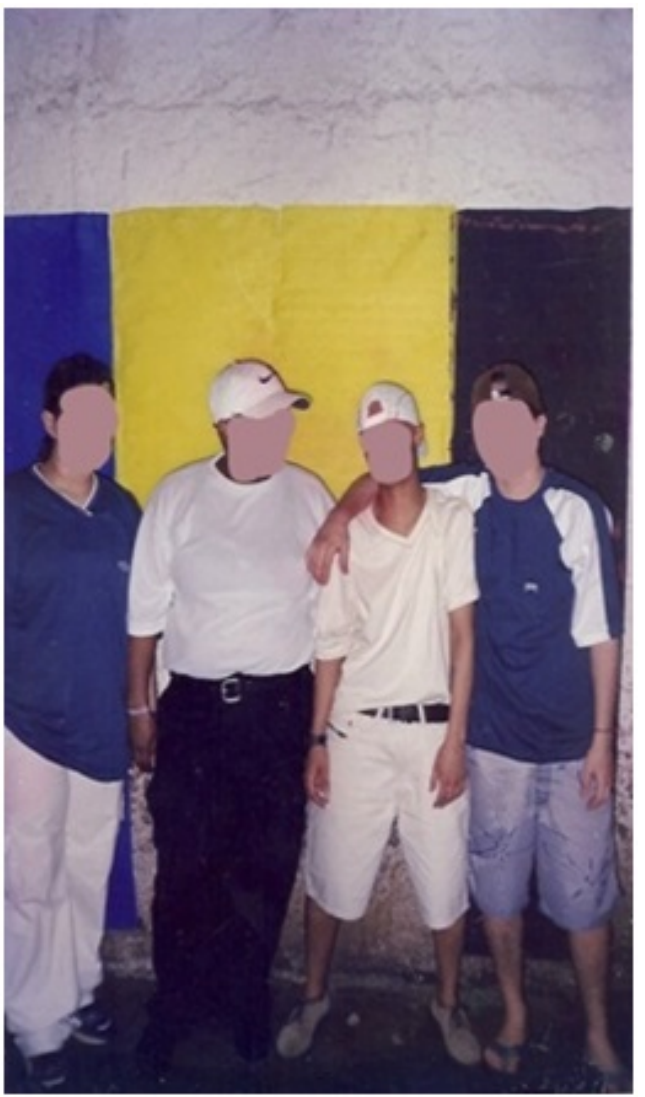

Fonte: Fotografias do arquivo pessoal de Mariana Coelho Torres, 2002.

A transformação visual é bem rápida, já que as mulheres de gênero masculino cortam os cabelos bem curtos e passam a vestir-se como homens (Imagem 3). Ao se referirem a si mesmas e as outras internas generificadas no substantivo masculino, cada 'um deles' é reconhecido, a partir de então, por um apelido ou nome social ${ }^{18}$ masculino. Logo os gestuais do macho vão se tornando mais 'naturais' e os códigos masculinos vão se reforçando ao representarem 'homens reais'. Em contraponto, as mulheres que exercem o papel da fêmea procuram reforçar algumas características legitimadas como femininas (Imagem 4), como os cabelos longos, as unhas pintadas e compridas (o que as coloca na posição sexual 'passiva' caso haja relações sexuais com penetração), usando roupas mais decotadas, maquiagem, perfumes, bijuterias,
Imagem 4: Presas "femininas".

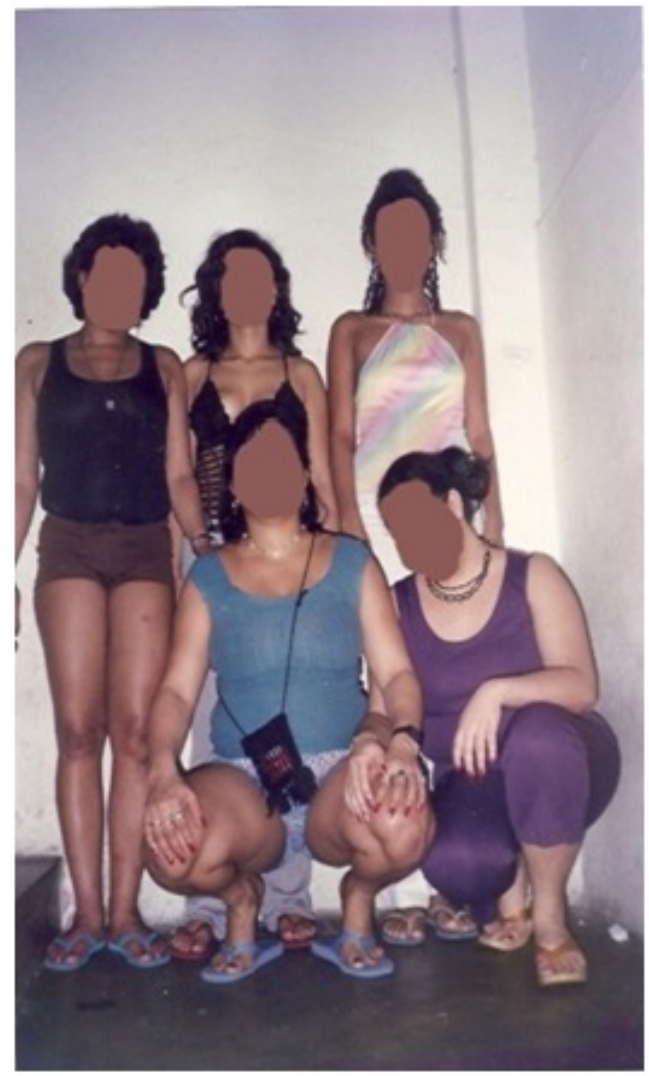

Fonte: Fotografias do arquivo pessoal de Mariana Coelho Torres, 2002.

etc. São elas que recortam ${ }^{19}$ a refeição servida e são responsáveis pela limpeza e arrumação da comarca, entre outros afazeres domésticos. Em troca, além do conforto afetivo, elas ganham proteção por parte daquelas que detém o poder de decisão e a força naquele espaço coletivo. Esse é o universo do gênero feminino das mulheres presidiárias, que precisam estar sempre bonitas e cheirosas para os 'seus maridos'. Assim sendo, os presídios femininos constituem espaços segregadores e discriminatórios, ainda que as relações homoafetivas sejam coletivamente aceitas.

Em alguns casos, uma mulher ao manter relação afetiva na cadeia com outra interna está satisfazendo as suas necessidades sexuais e emocionais (a carência afetiva é um dos mais graves problemas psicológicos 
enfrentados pelas detentas), em outros, todavia, essa relação entre mulheres ocorre na intenção delas fortalecerem o seu poder no sistema carcerário das mais diferentes formas. Como se trata de um espaço de mulheres, a possibilidade de ser construída a figura do macho ali dentro se dá através da segmentação da relação afetiva entre elas, estabelecendo-se que uma das duas deva exercer o papel definido para os homens pela sociedade ocidental patriarcal. Assim sendo, com essa definição de gênero, a detenta masculina passa a ter o poder $^{20}$ e a exercê-lo na escala da representação do grupo, tanto internamente quanto na conexão desse grupo com o sistema prisional. Tal condição dá a esses 'homens generificados' um papel chave para barganhar, exigir, cooptar e acordar com os instrumentos do poder instituído (há casos em que alguns desses 'homens', mais identificados com o poder prisional, recebem as melhores celas, mais comida, mais liberdade interna, mais poder de decisão nos seus micro-territórios e até o apoio da instituição para ficar com as 'mulheres mais bonitas').

A partir de uma perspectiva que entende que "o poder não é algo que se adquire, arrebate ou compartilhe; algo que se guarde ou deixe escapar; o poder se exerce a partir de inúmeros pontos e em meio a relações desiguais e móveis" (FOUCAULT, 1988, p.104), compreendemos o poder das presas 'masculinas' não apenas por elas se comportarem como tal, mas pelo modo como o comportamento delas influencia as relações de gênero cotidianamente desiguais no cárcere, portanto, as presas masculinas são mais poderosas nas decisões políticas do coletivo, mais poderosas nas possibilidades de escolha da parceira, mais poderosas das menores às maiores decisões cotidianas naquele território. Assim sendo, o espaço carcerário da cidade do Rio de Janeiro (RJ) reproduz as relações patriarcais em seu microuniverso social. Segundo Ornat (2009, p.186):

(...) Cada grupo socioespacial constrói culturalmente os papéis sociais a serem desenvolvidos por homens e mulheres, papéis estes relacionados hegemonicamente ao homem como provedor da família, tendo a mulher função de manter a família e a organização da casa. Como visto os papéis orientados a homens e mulheres nos relacionamentos contidos na sociedade heteronormativa são performaticamente buscados nos relacionamentos das travestis.

A presa feminina está ali para servir a presa masculina, assim como nas sociedades patriarcais a mulher se submete ao homem em relações desiguais, além de ocupar uma localização subalterna na configuração espacial.

\section{Por Políticas de Saú de Pública mais Plurais no Sistema Penitenciário da Cidade do Rio de Janeiro (RJ)}

É importante salientarmos neste trabalho a importância da consideração das questões de gênero e da diversidade sexual na gestão pública, na medida em que entendemos que:

a partir do momento em que ignoramos as especificidades de gênero, corremos o risco de cair em uma armadilha (...) negando-se a necessidade de um recorte de grupo específico estamos ofuscando importantes aspectos culturais e ideológicos (...). Isso se aplica da mesma forma aos espaços carcerários. Como pensar em políticas públicas específicas para a 
população encarcerada ignorando as características singulares desses espaços, compreendendo-os, portanto, de forma homogênea? É impossível (FIORAVANTE, 2011, p.4).

Apesar das relações apresentadas neste trabalho fazerem parte da paisagem prisional cotidiana de milhares de mulheres, o poder público parece não enxergar (ou enxergar lentamente) as demandas que essa organização social enseja.

Das políticas de educação sexual oferecidas pela instituição prisional no Rio de Janeiro (RJ), a grande preocupação é quanto a contaminação pelo vírus HIV nas relações sexuais entre os presos do sistema penitenciário masculino, sendo que em algumas unidades, camisinhas masculinas são doadas. Todavia, entre as mulheres, camisinhas femininas não são distribuídas, e não são informadas quanto as possibilidades delas serem contaminadas com outras doenças sexualmente transmissíveis (DST) via relações sexuais entre mulheres. Tampouco há uma dinâmica educativa e de conscientização acerca dos direitos das homossexuais femininas. A fala de Amanda nos mostra como as mulheres encarceradas estão esquecidas pelos gestores públicos da cidade do Rio de Janeiro (RJ):

Das políticas de educação sexual oferecidas pela instituição prisional no Rio de Janeiro (RJ), a grande preocupação é quanto a contaminação pelo vírus HIV nas relações sexuais entre os presos do sistema penitenciário masculino, sendo que em algumas unidades, camisinhas masculinas são doadas. Todavia, entre as mulheres, camisinhas femininas não são distribuídas, e não são informadas quanto as possibilidades delas serem contaminadas com outras doenças sexualmente transmissíveis (DST) via relações sexuais entre mulheres.
Tampouco há uma dinâmica educativa e de conscientização acerca dos direitos das homossexuais femininas. A fala de Amanda nos mostra como as mulheres encarceradas estão esquecidas pelos gestores públicos da cidade do Rio de Janeiro (RJ):

(...) às vezes ia o pessoal da saúde lá dá palestra, distribuir camisinha, passar vídeo de como se prevenir na relação sexual. E o que isso importava pra gente? É tudo falando de relação entre homem e mulher, só que a maioria das mulheres lá é do babado ${ }^{21}$, entendeu? A gente ia vê porque era obrigada ou porque não tinha nada pra fazer, mas não era do nosso interesse (...), se ainda fosse de mulher com mulher (...) (Exinterna, quando indagada sobre ter tido ou não o contato com a temática de gênero e sexualidades quando estava presa, 2012).

É necessária uma atenção mais direcionada para essas questões por parte dos gestores públicos, que devem entender o espaço carcerário em sua diversidade e particularidade. De acordo com Fioravante (2011), a espacialidade construída e vivida pelas mulheres no cárcere é "proveniente da junção de diversas corporalidades, cada uma delas apresentando características específicas, maneiras específicas de ver o mundo" (p.5). Ainda que os presídios femininos sejam orientados pela lógica heteronormativa, há neles pessoas de gêneros e sexualidades diferentes, portanto pertencentes a diferentes espacialidades. Essas diferenças não podem ser esquecidas e a diversidade deve ser contemplada na elaboração e implementação de políticas públicas e na redefinição das perspectivas do poder hegemônico nesses ambientes, que já tão distantes dos direitos sociais dos heteronormativos, quanto mais da 
extensão desses direitos na esfera dos grupos homoafetivos.

\section{Considerações Finais}

A organização espacial orientada, de maneira hegemônica, pela valorização das práticas heterossexuais, constrói o que chamamos de sociedade heteronormativa. A realidade, nessa perspectiva, é vivida e concebida a partir da lógica heterossexual e as pessoas que se comportam de maneira diferente são mantidas à margem da normalidade dominante e os espaços passam a ser regidos por essa normalidade, não se permitindo que outras expressões tenham a mesma liberdade. Nesse contexto, o conceito de gênero é idealizado, de maneira limitada, por gestores públicos e pouco utilizado pelos pesquisadores das Ciências Sociais brasileiras. Sob a ótica da heteronormatividade é estabelecido que o gênero seja uma definição ligada ao sexo do indivíduo, sendo os ideais de masculinidade e feminilidade concebidos unicamente a partir das normas heterossexuais.

Neste artigo, vimos que a sociedade atual é formada por diferentes histórias de indivíduos com diferentes hábitos e costumes, caracterizando-se pelo que chamamos de sociedade plural, mas essa diversidade não é reconhecida e respeitada, para que tenhamos, de fato, um vislumbre de democracia nas relações socioespaciais. Apesar da pluralidade identificada, o espaço é produzido e reproduzido por meio de uma única lógica e a sociedade heteronormativa prega um modelo de comportamento pré-estabelecido que deva ser seguido por todos. Esse modelo é imposto e pouco flexível, o que o faz responsável pela produção de espaços de opressão e sofrimento. Sinalizando nessa direção, vimos como nos presídios femininos da cidade do Rio de Janeiro (RJ) a heteronormatividade é imposta nas relações afetivas, revertendo ordens e escamoteando relações sexuais plurais que são travestidas, a partir da relação binária 'macho-fêmea', em heterossexualidade dominante.

Vimos que os presídios femininos na cidade do Rio de Janeiro (RJ), apesar de serem frequentados majoritariamente por mulheres, são espaços vivenciados por diferentes gêneros. Os espaços carcerários femininos cariocas reproduzem as relações patriarcais em um microuniverso social, cujo pertencimento ao gênero masculino é condição para garantia de privilégios, como ter mais força nas decisões para o coletivo.

Nesses ambientes, o homem é o 'todo poderoso' e, para que as presas construam a figura do homem em um ambiente de mulheres, as detentas transformam seus corpos ao máximo para que pareçam 'machos'. A transformação e a vivência das identidades de gênero, tanto masculina como feminina, é baseada em um código de conduta construído por elas mesmas, a partir de uma memória comum, resultado de vivências coletivas das presas em tempos passados, que refletem em seus comportamentos nos dias atuais.

Analisando os ambientes carcerários femininos da cidade do Rio de Janeiro (RJ), vimos também a falta da consideração das relações de gênero e sexualidades na gestão pública. Essas relações são expressivas nos presídios cariocas, mas apesar dessa sinalização, o poder público parece enxergálas muito lentamente. Iniciativas como a garantia do direito à visita íntima a presos e presas homossexuais foi um grande passo no caminho do reconhecimento por partes dos gestores da importância da consideração das relações de gênero e sexualidades. Todavia, iniciativas como essas devem deixar de ser pontuais e se tornarem, de fato, efetivas para o estabelecimento e a execução de políticas públicas que considerem a diversidade.

Essa pesquisa aponta para a necessidade

Mariana Coelho Torres e Augusto Cesar Pinheiro da Silva 
de transformação dos espaços heteronormativos através da educação em todos os níveis; das leis das diferentes instâncias do poder público; da mídia que aceite outras formas de expressão da sexualidade humana, para que possamos construir uma sociedade menos opressora. Reconhecemos o espaço como um elemento fundamental para essa mudança, pois é nele que essa lógica pode ser transformada e subvertida. Considerando a diversidade pela qual o homem é exposto atualmente, a sociedade não poderia mais aceitar a discriminação e naturalização das desigualdades e, ao eliminar a heteronormatividade em função de uma plurinormatividade, a sociedade poderia ser muito mais solidária e coletiva em outros projetos que buscam equidade e igualdade em todos os níveis e escalas.

1 Expressão cunhada nos anos de 1960 pelo então policial e delegado de polícia Guilherme Godinho Ferreira, o Sivuca, que, mais tarde, foi eleito deputado estadual pelo Rio de Janeiro (RJ) e que comandou a Scuderie Le Cocq, famoso grupo de 'policiais de elite' associados ao extermínio de bandidos, nos anos de 1960 a 1980 .

2 Pesquisa realizada por Mariana Coelho Torres no Grupo de Pesquisa Gestão Territorial no Estado do Rio de Janeiro (GeTERJ), do Depto de Geografia da PUCRio, na linha de pesquisa 'Políticas Públicas e Gênero no Rio de Janeiro’, entre 2009 e 2012.

3 Quando a pesquisadora do grupo foi levar a solicitação de investigação ao Núcleo de Pesquisa da Secretaria de Administração Penitenciária do Estado do Rio de Janeiro, a atendente, após ler a solicitação, de maneira espantosa, indagou: "Geografia?" Em seguida deixou escapar que nunca tinha visto projetos que não fossem da área do Direito ou da Psicologia serem aprovados.

4 A pesquisadora do GeTERJ foi visitante do sistema prisional carioca em instituições masculinas e femininas, no período de dezembro de 2000 a outubro de 2003.

5 A referência, no Brasil, nesta área do conhecimento geográfico é a Professora Joseli Maria Silva, do Departamento de Geografia da Universidade Estadual de Ponta Grossa (UEPG), do Paraná.

6 Esse medo se refere a dois motivos bem claros: o primeiro deles é que as expresidiárias têm, como um dos seus códigos de conduta, a não explanação dos acontecimentos do seu coletivo para quem é de fora desse grupo social; o segundo se refere à 'preocupação natural' dessas pessoas cujas sexualidades fogem do modelo heteronormativo, já que ficam acanhadas em falar das situações de preconceito pelas quais passaram e ainda passam, cotidianamente.

7 Para entender melhor sobre ocidentalização do mundo, buscar a discussão de Latouche (1996).

8 Para uma maior compreensão dos ideais das geógrafas feministas sobre o patriarcado e a sociedade patriarcal, ver Linda McDOWELL (1999).

$9 \quad$ Por mais que em uma democracia os direitos sejam garantidos por lei, a sociedade, de maneira geral, não aceita comportamentos desestruturantes do status quo.

10 Organização não governamental que tem como missão atuar na promoção da autoestima e cidadania da população LGBT no Brasil. 
11 Exceções à aridez de análises geográficas sobre $\mathrm{o}$ entrecruzamento de sistema prisional e as identidades de gênero são os ótimos trabalhos desenvolvidos por FIORAVANTE, Karina Eugenia. 'O espaço carcerário e a reestruturação das relações socioespaciais cotidianas de mulheres infratoras na cidade de Ponta Grossa, Paraná', de 2011 e a dissertação de mestrado de CHIMIN JÚNIOR, Alides Baptista: 'O espaço como componente de vulnerabilidade aos atos infracionais desenvolvidos por adolescentes do sexo masculino em conflito com a lei em Ponta Grossa, Paraná', ambos resultados de pesquisas desenvolvidas no grupo GETE, coordenado pela Profa. Joseli Maria Silva.

12 Neste trabalho, código de conduta é compreendido como normas de comportamento herdadas da tradição da vivência naquele espaço. Tradição aqui é entendida como memória coletiva, é a influência da organização de uma sociedade no passado e sua influência sobre os dias atuais (GIDDENS, 1997).

13 Para maior esclarecimento acerca da dimensão simbólica do território, buscar HAESBAERT, 2006..

14 Expressões típicas do linguajar simbólico das presas.

15 Nesta pesquisa serão usados nomes fictícios para os entrevistados, na intenção de proteger suas identidades.

16 Nome utilizado pelas internas para denominar seus 'quartos', que são pequenas áreas dentro das celas separadas umas das outras por cortinas de pano, para que os casais tenham um pouco de privacidade nas celas coletivas.

17 Diferente dos presídios masculinos, onde os presos homossexuais são permanentemente hostilizados, nos ambientes prisionais femininos existe a cela específica (denominada de 'cela dos gays') para as homossexuais que não são aceitas no coletivo heteronormatizado.

18 É o nome escolhido pelas pessoas que assumem identidade de gênero diferente da condição biológica de seus corpos e pelo qual desejam ser chamadas.

19 'Recortar a comida' é a expressão utilizada pelas presas para a tentativa de melhorarem a comida distribuída nos presídios. É comum as presas requentar na 'perereca' (nome pelo qual as presas chamam seus 'fogões' feitos com resistência de chuveiro elétrico) a comida servida, acrescentando temperos e outros ingredientes.

20 Poder aqui é compreendido como um conjunto de relações que hierarquizam os indivíduos nas organizações espaciais. Tais relações, inerentes às sociedades, devem ser sempre contextualizadas e relativizadas. Para um maior esclarecimento acerca dessa categoria, ver Michel Foucault (1987).

21 Expressão utilizada pela interna pra dizer que a maioria das mulheres encarceradas mantém relação homoafetiva.

\section{Referências}

BUTLER, Judith. Language, poder y identidad. Madrid, Routledge, 2009.

Gender trouble: feminism and the subversion of identity. London, Routledge, 1990.

CHIMIN JÚNIOR, Alides Baptista. O espaço como componente de vulnerabilidade aos atos infracionais desenvolvidos por adolescentes do sexo masculino em conflito com a lei em Ponta Grossa, Paraná. 
Dissertação de mestrado (Área: Geografia). Depto de Geografia, UEPG, 2009.

COSTA, Carmem Lúcia; SANTOS, Juliana Jesus. "Curso Gênero e Diversidade na Escola: novos olhares, novas experiências". In: ANAIS do I Seminário Latino-Americano de Geografia e Gênero / Pré- encontro da Conferência Regional da UGI, Rio de Janeiro, 2011, p.776-798.

Dicionário Houaiss da Língua Portuguesa. Disponível em Dicionário Eletrônico Houaiss da Língua Portuguesa. 2.0a. Programa de computador. Acessado em 02 de março de 2012.

FACCO, Lúcia. "A escola como questionadora de um currículo homofóbico". In: SILVA, Augusto César Pinheiro da; SILVA, Joseli Maria. (Org.) Espaço, Gênero e Poder: conectando fronteiras. Ponta Grossa: Todapalavra, 2011.

FERREIRA, Eduarda. "Questões de gênero e orientação sexual em espaço escolar". In: SILVA, Augusto César Pinheiro da; SILVA, Joseli Maria. (Org.) Espaço, Gênero e Poder: conectando fronteiras. Ponta Grossa: Todapalavra, 2011.

FIORAVANTE, Karina Eugenia. "O espaço carcerário e a reestruturação das relações socioespaciais cotidianas de mulheres infratoras na cidade de Ponta Grossa, Paraná". In: ANAIS do IX Encontro Nacional da Associação Nacional de Pós-Graduação e Pesquisa em Geografia, Goiânia, 2011.

FOUCAULT, Michel. História da Sexualidade I: a vontade de saber. Rio de Janeiro: Graal, 1988.

Vigiar e Punir: nascimento da prisão. Petrópolis: Vozes, 1987.
FREIRE, Paulo. Pedagogia do oprimido. 50.ed. Rio de Janeiro: Paz e Terra, 2011.

GIDDENS, Anthony. "A vida em uma sociedade pós-tradicional". In: BECK, Urich; GIDDENS, Anthony; LASH, Scott (Org.). Modernização Reflexiva. São Paulo: UNESP, 1997.

GOFFMAN, Erving. Manicômios, Prisões e Conventos. São Paulo: Perspectiva, 2005.

HAESBAERT, Rogério. O mito da desterritorialização: do "fim dos territórios" à multiterritorialidade. Rio de Janeiro: Bertrand Brasil, 2006.

$\begin{array}{llr} & & \text { "Concepções - de } \\ \text { território para } & \text { entender a } \\ \text { desterritorialização" } & \text { In. Territórios, }\end{array}$
territórios. Programa de Pós-Graduação Geografia - PPGEO - UFF/AGB - Niterói, 2002.

HALL, Stuart. "The West and the Rest: Discourse and Power". In: HALL, Stuart; GIEBEN, Bram (Org.). Formations of Modernity. Cambridge: Polity Press, 1992), 275-331.

JUNIOR, Xisto Serafim de Santana de Souza. "A análise do discurso como estratégia na identificação das intencionalidades e práticas espaciais dos movimentos sociais urbanos de João Pessoa - PB". In: RAMIRES, Julio Cesar de Lima; PESSOA, Vera Lúcia Salazar (Org.). Geografia e Pesquisa Qualitativa: nas trilhas da investigação. Uberlândia: Assis, 2009.

LATOUCHE, Serge. A Ocidentalização do Mundo: ensaio sobre a significação, o alcance e os limites da uniformização planetária. Petrópolis: Vozes,1996.

LOURO, Guaraci Lopes. Um corpo 
estranho: ensaios sobre sexualidade e teoria queer. Belo Horizonte: Autênntica, 2004.

MASSEY, Doreen. Pelo espaço: uma nova política da espacialidade. 2 ed. Rio de Janeiro: Bertrand Brasil, 2009.

MATOS, Patrícia Francisca de; PESSÔA, Vera Lúcia Salazar. "Observação e Entrevista: construção de dados para a pesquisa qualitativa em geografia agrária". In RAMIRES, Julio Cesar de Lima; PESSOA, Vera Lúcia Salazar (Org.). Geografia e Pesquisa Qualitativa: nas trilhas da investigação. Uberlândia: Assis, 2009.

McDOWELL, Linda. Gender, identity and place: understanding feminist geographies. Minneapolis: UnUniversityota Pres, 1999.

ORNAT, Jose Marcio. "Espacialidades travestis e a instituição do território paradoxal". In: SILVA, Joseli Maria. (Org.) Geografias Subversivas: discursos sobre espaço, gênero e sexualidades. Ponta Grossa: Todapalavra, 2009.

SANTOS, Cláudia Reis dos. "Borrando Fronteiras: uma visão ampliada entre sexualidades e escolas". In SILVA, Augusto César Pinheiro da; SILVA, Joseli Maria. (Org.) Espaço, Gênero e Poder: conectando fronteiras. Ponta Grossa: Todapalavra, 2011.

SANTOS, Milton. A Natureza do Espaço: Técnica e Tempo, Razão e Emoção. São Paulo: Edusp, 2008.

SILVA, Joseli Maria et al. "Espaço, Masculinidades e adolescentes em conflito com a lei". In GeoUERJ, ano 14, n. 23, v.1, $1^{\text {o }}$ semestre de 2012. Rio de Janeiro / EdUERJ, 2012, p.136-166.

\section{(Org.) Geografias}

Subversivas: discursos sobre espaço, gênero e sexualidades. Ponta Grossa: Todapalavra, 2009.

- Gênero e Sexualidade na análise do espaço urbano. Geosul, v.22, n.44, p.117-134, 2007.

. "Análise do espaço sob a perspectiva de gênero: um desafio para a geografia cultural brasileira". In ROSENDHAL, Zeny; CORREAA, Roberto Lobato. (Org.) Geografia: temas sobre cultura e espaço. Rio de Janeiro: EdUERJ, 2005.

SOUZA, Marcelo Lopes de. "O território: sobre espaço e poder, autonomia e desenvolvimento". In: CASTRO, Iná Elias de; GOMES, Paulo Cesar da Costa; CORREA, Roberto Lobato. (Org). Geografia: conceitos e temas. Rio de Janeiro: Bertrand Brasil, 2000, p.77-115.

Recebido em 18 de junho de 2013. Aceito em 14 de outubro de 2013. 